\title{
LOGÍSTICA REVERSA COMO MECANISMO PARA REDUÇÃO DO IMPACTO AMBIENTAL ORIGINADO PELO LIXO INFORMÁtICO
}

\section{1- Byron Acosta \\ Universidade Federal do Rio Grande do Sul - UFRGS bfaandino@ea.ufrgs.br}

\section{3- Antonio Domingos Padula \\ Universidade Federal do Rio Grande do Sul - UFRGS adpadula@ea.ufrgs.br}

\author{
2- Douglas Wegner \\ Universidade Federal do Rio Grande do Sul - UFRGS \\ dwegner@ea.ufrgs.br
}

\section{RESUMO}

A logística reversa é um processo de planejamento, implementação e controle da eficiência e custo efetivo do fluxo de matérias-primas, produtos em processo e produtos prontos e informações relacionadas ao produto, do ponto de consumo para o ponto de origem do produto, com a finalidade de recuperar o valor ou destinar à apropriada disposição, com um enfoque ambientalmente correto. No setor de fabricação e comercialização de produtos informáticos os sistemas de logística reversa são implementados cada vez mais com a finalidade de reaproveitar os produtos depois do fim de vida útil, como uma via rentável de redução de custos, maximizando o uso de matérias-primas que impactam diretamente na redução de lixo informático. O presente artigo busca identificar como é o processo de logística reversa de produtos informáticos aplicado por uma empresa Atacadista. Através de um estudo de caso identificou-se que a empresa utiliza um sistema de logística reversa de pós-venda parcial para produtos com defeitos de fábrica que são revalorizados por meio de remanufatura, reuso e venda de produtos ou peças em mercados secundários. Além disso, observou-se que não existe reciclagem para a separação e aproveitamento de materiais primários, sendo que as peças que poderiam ser recicladas vão diretamente para um aterro.

\section{ABSTRACT}

Reverse logistics is a process of planning, implementation and control of efficiency, and cost effective of the raw material flows, goods in process, ready products and information related to product. From the consumption point to the origin point, with aim to recover the product in an environmentally correct way. In the computer manufacture and marketing sector, reverse logistic systems are increasingly implemented in order to reuse the products after the end of life for decrease costs, maximizing the use of raw materials that directly impact on the reduction of computer waste. This article seeks to identify how the process of reverse logistic of computer products is applied by a wholesaler. A case study identified that the company uses a reverse logistic system to defect products which are revalued by remanufacture, reuse and sale of products or parts in secondary markets. Moreover, there is no separation for recycling and use of primary materials and the parts that could be recycled goes directly to a landfill. trash. 


\section{Introdução}

A rápida evolução tecnológica, com constantes inovações, novas versões, melhoras de rendimento e uso, faz com que os produtos de informática (computadores, impressoras, software e periféricos) tenham um ciclo de vida cada vez mais curto (TAN et $\mathrm{al}, 2003)$. Mesmo que a vida útil estimada de computadores seja de dez anos, na prática nos primeiros três ou quatro anos de utilização tornamse obsoletos devido às exigências de novos programas ou novas versões dos sistemas operativos (SALINAS, 2007).

Os fabricantes de produtos de informática têm melhorado seus processos ao longo dos anos, com a finalidade de aumentar sua produção e reduzir custos, ou seja, aumentar sua eficiência para que os computadores cheguem ao mercado com preços mais baixos e possibilitando que um número maior de pessoas possa adquiri-los. Outra forma de redução de custos neste mercado é a produção e montagem de computadores genéricos, os denominados clones, que concorrem com as marcas já estabelecidas no mercado a um preço muito menor.

Inovações em produtos informáticos ocorrem todos os dias: um computador que é comprado hoje, em pouco tempo já tem uma nova versão, seja de tamanho, desenho, peso, capacidade, novos materiais e preço. Isto faz com que a vida útil deste tipo de produtos seja extremadamente curta, o que incentiva a aquisição de novas versões continuamente. Kang e Schoenung (2005) argumentam que o período de vida útil dos computadores pessoais nos Estados Unidos caiu de 4,5 anos em 1992 para somente 2 anos em 2006, acelerando a obsolescência dos equipamentos e seu conseqüente descarte. Além disso, os próprios fabricantes de produtos de informática utilizam estratégias de venda em que aceitam o computador ou impressora usada como parte do pagamento, para que o cliente compre a última versão do produto.

Como conseqüência desse alto índice de inovação do setor, a cada ano se descarta milhões de produtos informáticos em todas as partes do mundo, para serem substituídos por novos modelos. Estimativas da Environment Protection Agency - EPA, órgão governamental dos Estados Unidos, indicam que 30 a 40 milhões de computadores serão descartados em cada um dos próximos anos (CARROLL, 2008), resultado da desatualização dos equipamentos. $O$ autor destaca também dados das Nações Unidas que estimam o total mundial de lixo eletrônico em 45 milhões de toneladas anuais. Segundo Carroll (2008), o percentual de reciclagem desse tipo de lixo é inferior a $20 \%$ nos Estados Unidos e uma grande parcela é enviada para países subdesenvolvidos para extração de peças ou para reaproveitamento local.

A partir desse contexto, cabe questionar o que as empresas que produzem e comercializam produtos informáticos fazem com os itens obsoletos ou estragados de seus clientes? Que processos de tratamento ou reciclagem dos computadores eles aplicam? Com base nessa problemática, o presente artigo busca identificar qual é o processo de logística reversa de computadores, impressoras, periféricos e componentes informáticos no fim da vida útil e com defeitos de fabricação, utilizados por uma empresa atacadista de informática no Equador.

O artigo está estruturado da seguinte forma: inicialmente discute-se a questão da sustentabilidade na gestão estratégica e caracteriza-se o que é logística reversa, sua importância e como funciona o processo de logística reversa de produtos de informática no fim de vida útil ou com defeitos de fabricação. Em seguida são discutidos a degradação e o impacto ambiental de componentes utilizados em equipamentos de informática. Assim, se procede à análise do caso da segunda maior empresa atacadista de informática do Equador e como ela realiza a logística reversa do lixo informático gerado pelo giro de seu negócio. O artigo é finalizado com discussões sobre o caso, limitações do estudo e indicações para novas pesquisas.

\section{Gestão Estratégica e Sustentabilidade}

A busca por estratégias competitivas sustentáveis, por parte de muitas empresas, já pode ser percebida no ambiente organizacional. Mais do que obter os maiores lucros possíveis, a qualquer custo, as organizações têm se preocupado em estabelecer estratégias que incluam a sustentabilidade ambiental e social, além da econômica. Isso se deve a exigências legais, impostas por governos preocupados com as conseqüências das organizações, mas também devido a pressões da própria sociedade e do mercado consumidor (MARIEN, 1998). A visão estratégica tradicional, na qual o fluxo de bens em uma cadeia de suprimentos termina com 0 consumidor, está mudando rapidamente. De maneira crescente, indústrias e fornecedores começam a ser responsabilizados pelos resíduos 
gerados pelo uso de seus produtos por parte dos consumidores finais.

Mais do que um custo, Marien (1998) afirma que muitas empresas têm olhado para a sustentabilidade de suas ações e para a logística reversa como uma recuperação de investimento, tanto através do reaproveitamento de materiais como pela geração de uma imagem positiva da organização perante o mercado. À medida que os consumidores tornam-se mais preocupados com 0 ambiente, as empresas precisam ir além do simples recebimento de insumos e envio de produtos ao longo da cadeia. "Elas podem obter vantagem competitiva real rejeitando a noção convencional de que, uma vez que o produto esteja fora da porta da empresa, a gestão dos resíduos torna-se problema dos outros" (MARIEN, 1998, p. 4).

Mollenkopf e Closs (2005) argumentam que muitas companhias têm visto a logística reversa como uma atividade estratégica que pode, inclusive, ampliar a competitividade da empresa e da cadeia ao longo do tempo. De uma perspectiva mercadológica, a adoção de políticas de recolhimento de produtos obsoletos pode aumentar a percepção dos consumidores sobre a qualidade dos produtos e melhora a imagem da empresa. Do ponto de vista logístico, os autores acreditam que também seja possível obter vantagens, reutilizando componentes e reduzindo custos. No entanto, a estratégia precisa ser baseada na sustentabilidade econômica, viabilidade técnica e suporte social para que o programa seja bem sucedido.

Como forma de ressaltar a importância de adotar estratégias que envolvam a sustentabilidade ambiental, Hart (1995) propõe a adoção de uma visão baseada em recursos "natural". O autor acredita que no futuro será inevitável que as empresas e os mercados sejam limitados e dependentes dos ecossistemas naturais. "Em outras palavras, é provável que estratégia e vantagem competitiva nos próximos anos sejam baseadas nas capacidades que facilitem a atividade econômica sustentável ambientalmente" (HART, 1995, p. 991). Isto é, as empresas precisam criar estratégias para minimizar os impactos que seus produtos causam sobre o meio ambiente e encontrar maneiras de retirar do mercado e reaproveitar os produtos fora de uso que podem causar danos aos recursos naturais.

Hart (1995) afirma ainda que pesquisas sugiram que há no mercado um grande espaço não utilizado com respeito a desempenho ambiental corporativo. Empresas capazes de formular e implementar estratégias sustentáveis do ponto de vista ambiental podem gerar uma imagem positiva capaz de viabilizar essa estratégia economicamente. Uma estratégia de logística reversa, com o apoio dos principais stakeholders externos pode prover um meio de a empresa requisitar no mercado uma imagem de sustentabilidade e preocupação com os recursos naturais.

\subsection{Logística Reversa}

A meta de quase todo negócio é reter os clientes de forma que eles não consumam os produtos da concorrência. Adotar e implementar políticas de logística reversa é um dos caminhos estratégicos que as empresas têm desenvolvido nos últimos anos para que o custo de mudança do consumidor seja mais alto (TAN; YU; ARUM, 2003). Assim, logística reversa é um processo de planejamento, implementação e controle da eficiência e custo efetivo do fluxo de matériasprimas, produtos em processo, produtos terminados e informações relacionadas ao produto, do ponto de consumo para o ponto de origem do produto, com a finalidade de recuperar o valor ou destinar à apropriada disposição (ROGERS; TIBBEN-LEMBKE, 1998).

Segundo Leite (2006, p. 16-17):

A logística reversa é uma área da logística empresarial que planeja, opera e controla o fluxo e as informações logísticas correspondentes, do retorno dos bens de pós-venda e de pós-consumo, ao ciclo de negócio ou ao ciclo produtivo, por meio dos canais de distribuição reversos, agregando-lhes valor de diversas naturezas: econômico, ecológico, legal, logístico, de imagem corporativa, entre outros.

Dentro desta definição é importante explicar o que são canais de distribuição reversos, como a base de tudo o que constitui um sistema de logística reversa. Leite (2006) identifica dois tipos de canais de distribuição reversa, de pós-consumo e de pós-venda.

\section{a) Os canais de distribuição reversa de pós- consumo}

Estão constituídos pelo fluxo reverso de produtos e de materiais originados no descarte de produtos, depois de finalizada sua utilidade principal (fim de vida útil) e que retornam ao ciclo produtivo de alguma forma (revalorização). Uma vez que o produto atinge seu fim de vida útil, este pode ser revalorizado por meio do canal reverso de desmanche ou de reciclagem. Se por nenhum destes meios o bem de pós-consumo conseguiu ser revalorizado encontra a disposição final em aterros sanitários ou é incinerado. 
O desmanche é um sistema de revalorização de um produto que sofre um processo industrial de desmontagem pelo qual seus componentes em condições de uso são enviados para remanufatura e ao mercado de peças usadas. Na reciclagem, os materiais constituintes dos produtos são extraídos industrialmente, transformando-se em matériasprimas secundárias ou recicladas que serão reincorporadas à fabricação de novos produtos. Tanto no desmanche como na reciclagem os materiais não reutilizáveis são enviados a aterros sanitários ou são incinerados.

Nos canais de distribuição reversa de pósconsumo destacam-se três subsistemas: reuso, reciclagem de materiais e incineração (LEITE, 2006). Sistemas de reciclagem agregam valor econômico, ecológico e logístico aos bens de pósconsumo, criando condições para que o material seja reintegrado ao ciclo produtivo e substituindo as matérias-primas novas. O sistema de reuso agrega valor de reutilização ao bem de pós-consumo. E o sistema de incineração agrega valor econômico, pela transformação dos resíduos em energia elétrica.

O objetivo econômico da implementação da logística reversa de pós-consumo é a obtenção de resultados financeiros por meio de economias obtidas nas operações industriais, principalmente pelo aproveitamento de matérias-primas secundárias, provenientes dos canais reversos de reciclagem, ou de revalorizações nos canais reversos de reuso e de remanufatura (LEITE, 2006).

\section{b) Os canais de distribuição reversos de pós- venda}

Estão constituídos pelas diferentes formas de retorno de produtos, com pouco e nenhum uso, que fluem no sentido reverso, do cliente ao varejista ou ao fabricante, do varejista ao fabricante. Os canais reversos de pós-venda utilizam em grande parte os próprios agentes da cadeia de distribuição direta. Este fluxo reverso se origina por problemas de desempenho do produto, ou por garantias de fábrica; também pode se originar em diferentes momentos da cadeia de distribuição direta. Os problemas mais comuns que geram este fluxo reverso são: avarias de transporte, garantia dada pelo fabricante, erros de pedido, limpeza do canal nos elos da cadeia de distribuição, excessos de estoques, fim de estação, fim de vida comercial do bem e estoques obsoletos entre outros.

Leite (2006) afirma que as quantidades de produtos que fluem nos canais reversos de pós- venda variam de acordo com o tipo de produto, ou seja, características como sazonalidade, ciclo de vida útil, rotação de estoques, sistema de comercialização estabelecido, obsolescência, impacto do retorno no resultado operacional e condições tecnológicas de remanufatura. A devolução por motivo de defeito ou de problema de qualidade em geral requer decisão de natureza técnica em um dos elos da cadeia de distribuição direta para definir o destino dos bens devolvidos. Assim, esses bens poderão ser dirigidos para o mercado primário ou secundário, processos de remanufatura, de reforma, de reciclagem de materiais constituintes ou para sistemas de disposição final.

Da mesma forma como o canal reverso de pósconsumo, o cana de pós-venda tem seu objetivo econômico, com uma visão estratégica de recapturar valor financeiro do bem através de revenda em mercados primários ou secundários, ganhos econômicos por meio de desmanche, remanufatura, reciclagem industrial e disposição final (LEITE, 2006).

\subsection{Determinantes da Logística Reversa}

Quatro são as determinantes que devem ser considerados para a implementação de um sistema de logística reversa: os fatores econômicos, a legislação, consciência social e meio ambiente e pensamento verde (RAVI; SHANKAR; TIWARI, 2005).

(i) Fatores econômicos: os recursos econômicos são escassos nas organizações, fazer uso eficiente deles é um problema que todas as empresas tentam resolver. Sob esta ótica, as empresas se esforçam continuamente para alcançar reduções de custo em seus processos de produção. Como parte desse processo, a logística reversa desenvolve diferentes opções de recuperação do produto obsoleto para remanufatura, reparação, reconfiguração e reciclagem que podem resultar em oportunidades de negócio lucrativas. A logística reversa é agora percebida como um investimento que gera retorno e não simplesmente como um custo que minimiza a administração do desperdício. O sistema pode trazer benefícios de custo para as empresas, enfatizando o reuso e redução de materiais, agregando valor aos produtos recuperados e reduzindo os custos de disposição do produto no fim de vida útil. 
(ii) Legislação: a legislação determina leis que obrigam as empresas a recuperar seus produtos ou aceitar de volta uma vez finalizada sua vida útil. Estas incluem a recuperação e reuso de produtos obsoletos, redução do volume de desperdício gerado e o aumento de uso de materiais reciclados. Existem também restrições na utilização de certos tipos de materiais que formam parte da composição do produto. Também se colocam restrições no uso de substâncias perigosas nos processos de produção, que facilitam o desmanche e reciclagem do desperdício eletrônico.

(iii) Consciência social: conjunto de valores e princípios que são implementados em empresas, organizações e na comunidade, com a finalidade de que os indivíduos incorporem responsavelmente atividades de logística reversa. Muitas vezes atividades de logística reversa podem melhorar a imagem corporativa da empresa, e ensinam aos clientes a adequada forma de consumir os produtos sem que afetem o meio ambiente.

(iv) Meio ambiente e pensamento verde: o foco da logística reversa está direcionado a atingir benefícios ambientais, proporcionando uma vantagem competitiva para as empresas que proativamente incorporam objetivos ambientais em suas práticas de negócio e planos estratégicos. A imagem "verde" de fabricação de produtos ambientalmente corretos tornou-se um elemento de marketing importante que estimula as empresas a explorar opções de recuperação de seus produtos no fim de vida útil.

Segundo Murphy e Poist (2000) a logística reversa forma parte das estratégias de logística verde que tem como foco reciclar materiais, reduzir o consumo e reutilizar materiais. Para Leite (2005), e Kenemeyer, Ponzurick e Logar (2002), as firmas justificam a implementação dos sistemas de logística reversa examinando cinco fatores estratégicos chave: custos estratégicos, qualidade global, atendimento ao consumidor, preocupações ambientais, preocupações legais e imagem corporativa. Nestes fatores é necessário realizar uma análise de custo - beneficio que relacione transporte, armazenagem, fornecedores, remanufatura/reuso, reciclagem e empacotado.

Para Ravi, Shankar e Tiwari (2005), a logística reversa inclui processos como reenvio da mercadoria quando o produto tem alguma falha de fabricação, inventário sazonal, reabastecimento, excesso de inventário, produtos não desejados ou versões antigas. Estas atividades também incluem programas de reciclagem, programas de tratamento de materiais perigosos, disposição de equipamento no fim de vida útil e recuperação do produto para reutilização. O fluxo reverso do produto é originado em vários pontos, mas deve ser consolidado somente em um destino. Assim, num sistema de logística reversa o fator crítico para seu sucesso é a identificação do mapa de fluxos, para entender a ordem, componentes e inter-relações dos processos que formam parte do sistema (STOCK, 1998).

As funções executadas ao longo das atividades de logística reversa incluem cuidado de materiais, redução do ciclo de tempo de disposição do produto, remanufatura e renovação, recuperação do produto e seus componentes, negociação com fornecedores, terceirização, gestão financeira e atendimento ou consumidor (RAVI; SHANKAR; TIWARI, 2005). Desta forma, a logística reversa se focaliza na administração de fluxos de matérias, informações e relações de criação de valor de produtos usados, para o aproveitamento de seus componentes, ou disposição deles em lugares seguros que não contaminem o meio ambiente.

\subsection{Logística Reversa no Setor de Computadores}

Cada vez mais o acelerado lançamento de inovações ao mercado cria um alto grau de obsolescência de produtos informáticos que reduz seu ciclo de vida, com uma clara tendência à descartabilidade. Computadores têm seus custos reduzidos e uma obsolescência acelerada, gerando produtos de ciclos de vida cada vez mais curtos (LEITE, 2006), seja por moda, status, novos modelos ou novas tecnologias.

Para Leite (2006) existem três categorias de bens produzidos: os bens descartáveis, os bens semiduráveis e os bens duráveis. Os computadores e seus periféricos se classificam dentro dos bens semiduráveis, porque apresentam duração média de vida útil de alguns meses, raramente superior a dois anos. Está é uma categoria intermediária que, sob o enfoque dos canais de distribuição reversos, apresenta tanto características de bens duráveis, como de bens descartáveis.

Hoje em dia, fabricantes de produtos eletrônicos reutilizam seus próprios produtos, devolvidos pelo consumidor ao fim da vida útil para recuperar os componentes e incorporá-los nas atividades regulares do processo de produção. De acordo com Lee e Dong (2007), duas são as motivações para que esta indústria recupere seus produtos. A 
primeira é a legislação, que tem como objetivo determinar políticas para que os fabricantes de produtos eletrônicos se responsabilizem pelo potencial dano ambiental que seus produtos geram no final da vida útil. A segunda é o alto potencial de lucro que o reuso de produtos obsoletos, componentes e materiais primários pode gerar. Isto fica mais evidente nos produtos de alta tecnologia, como é o caso dos computadores.

Assim, a logística reversa é extremamente praticada na indústria de fabricação de computadores (RAVI; SHANKAR; TIWARI, 2005). Uma das principais preocupações dessa indústria atualmente é desenho, avaliação e implementação de sistemas de logística reversa para a recuperação, reutilização e reciclagem de computadores em fim de vida útil.
A Figura 1 apresenta o framework de logística reversa para a cadeia de fornecedores de computadores. A gestão de operações de retorno na cadeia de recuperação compreende a coleta dos produtos desde o consumidor, inspeção dos produtos, reclassificação para reuso, remanufatura e reciclagem. $O$ processo continua com a redistribuição dos produtos ou partes recuperadas ao mercado original ou secundário. Quando o produto recuperado está no fim da vida útil, muitos destes componentes podem ser usados para sua função original em outros computadores. No entanto, como estes componentes não têm o mesmo desempenho que seus similares novos, os produtos montados são comercializados no mercado com preços baixos.

Figura 1: Framework de logística reversa para cadeia de fornecedores de computadores/hardware.

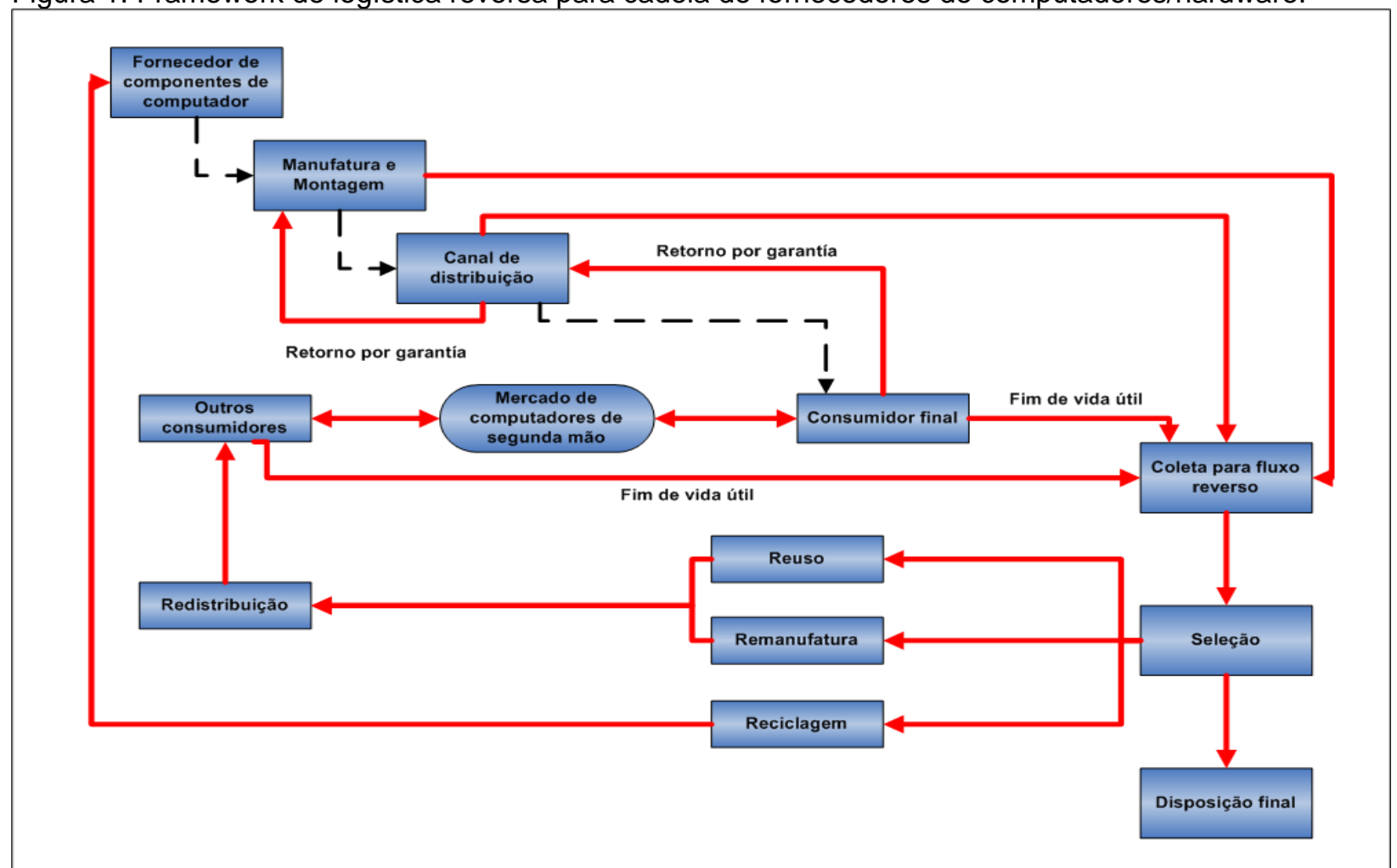

Fonte: Ravi e Shankar, 2005.

O principal objetivo para a logística reversa de computadores é criar e promover caminhos alternativos de ação para os produtos no fim de vida útil. Alguns de seus principais componentes podem ser diretamente reutilizados, como por exemplo a placa-mãe, que pode ser remanufaturada em brinquedos eletrônicos ao invés de ser enviada para os aterros como lixo, causando um dano ambiental (RAVI; SHANKAR, 2005). Esta visão de reciclagem para as empresas do setor começa no design do produto. Um exemplo disso é a Siemens que, em 1993, conseguir produzir um computador com 29 partes, em vez de 87 , como os modelos anteriores, o que resultou em economia de tempo importante, pois a montagem se faz em 7 minutos e a desmontagem em 4, enquanto para os modelos anteriores a duração era de 33 e 18 minutos, respectivamente (LEITE, 2006). 
Para Shih (2001) quatro são os stakeholders integrados num sistema de logística reversa para computadores no fim de vida útil: (1) Pontos de coleta, constituído pelos próprios atacadistas e pelo canal de distribuição varejista, (2) Locais de armazenagem, que atuam como uma ponte entre os pontos de coleta e as plantas de desmanche e reciclagem, (3) Desmanche e reciclagem, que são plantas onde se desmancham, desmontam, trituram e classificam os principais componentes do computador e (4) Mercado de materiais de segunda mão, tratamento final e aterro de lixo. Um quinto elemento, que não foi considerado, é o stakeholder dedicado ao recondicionamento e remanufatura de produtos. Em alguns casos são os próprios atacadistas e varejistas que fazem esta função, mas com escala de produção limitada.

\section{A Contaminação por Lixo Informático}

O lixo gerado por componentes eletrônicos como os computadores é um dos mais danosos para o meio ambiente, pela contaminação de seus materiais. A preocupação quanto aos efeitos nocivos do lixo tecnológico é nova e algumas empresas ainda não têm procedimentos que eliminem este problema. Segundo Leite (2006) a primeira conseqüência desse fato para a sociedade é o custo de destinação final desses excessos e, para as empresas, o custo negativo de sua imagem corporativa.

A contaminação através de produtos informáticos começa desde seu processo de fabricação, pelo uso de produtos químicos que geram gases poluentes e pela alta quantidade de água e energia que o processo consome, afetando terra, ar e água (ENVIRONMENTAL PROTECTION ADMINISTRATION, 1995). Três são os problemas ambientais relacionados com a fabricação de computadores: a utilização de muitas substâncias tóxicas no processo de produção, um consumo elevado de água e energia e a grande quantidade de resíduos tóxicos que geram (OPCIONS, 2003). Segundo a Environmental Protection Administration (1995) os produtos químicos utilizados em maior quantidade na fabricação de computadores são acetona, amoníaco, diclorometano, éter de glicol, metanol, metil etil cetona, freon 113, ácido sulfúrico, tolueno, tricloroetileno e xileno. Os materiais mais abundantes em um computado são plásticos, aço, silício e alumínio, mas também se utilizam metais pesados como o chumbo, cádmio e mercúrio, principalmente na fabricação de chips e placas, onde se utiliza elevado número de substâncias químicas poluentes e com efeitos cancerígenos (OPCIONS, 2003).

Para produzir um chip de memória (32 MB DRAM) de duas gramas se utilizam 1600 gramas de combustível, 72 gramas de substâncias químicas e 32 litros de água (WILLIAMS, 2004). Segundo Williams, Aryes e Heller (2002) para produzir um computador com monitor CRT, se utilizam $290 \mathrm{~kg}$ de combustível, $22 \mathrm{~kg}$ de substâncias químicas e 1500 litros de água. Assim também, de toda a eletricidade que consome um computador ao logo de sua vida (considerando 3 anos de uso), 83\% foram utilizados em seu processo de produção e apenas os 17\% restantes consumidos no seu uso diário (WILLIAMS; ARYES; HELLER, 2002).

O consumo de eletricidade de uma fábrica de chips representa aproximadamente $40 \%$ dos custos de produção, devido à utilização de ventiladores, bombas de ar e aspiradores necessários para as salas limpas; da mesma forma a fábrica consome 7 milhões de litros de água cada dia (OPCIONS, 2003)

Durante sua vida útil, os produtos de informática continuam gerando gases tóxicos pela sua utilização. Mesmo assim, até este estágio o impacto ambiental não é percebido de forma considerável. É no fim de sua vida útil que este problema fica mais evidente, visto que as empresas tentam por diferentes meios eliminar esses produtos obsoletos e não encontram a forma mais eficiente de fazer isso. Para Ahluwalia e Nema (2007) equipamentos de computação (hardware) podem ter 3 tipos diferentes de ciclos de vida do produto: a via original ou a primeira vida do produto (quando está sendo usando pelo primeiro usuário) e até duas vidas a mais dependendo do reuso. A duração do primeiro ciclo de vida do produto é de 2 a 4 anos para usuários corporativos, e de 2 a 5 anos para usuários domésticos. Assim, o fim de vida útil do produto começa no período que é descartado pelo primeiro usuário até quando o equipamento vai ser reciclado ou enviado para o aterro sanitário.

Segundo Opcions (2003) a produção de lixo eletrônico cresce três vezes mais rápido que de lixo urbano, um exemplo disto é o volume de lixo informático que cresce entre $16 \%$ e $28 \%$ a cada cinco anos. Da mesma forma $90 \%$ dos equipamentos informáticos obsoletos terminam nos aterros sanitários sem nenhum tratamento prévio para que não polua o meio ambiente.

Existem 3 opções para dispor do lixo informático: reuso, reciclagem e disposição no 
aterro sanitário. (KNEMEYER, PONZURICK; LOGAR, 2002; AHLUWALIA; NEMA, 2007). Segundo Ahluwalia e Nema (2007) a escolha de uma ou todas as alternativas deve ter como objetivo a minimização do custo, minimização do risco percebido e minimização do impacto ambiental. Quando os computadores são doados, eles sofrem pequenos recondicionamentos para que sua vida útil se prolongue um pouco mais, mas isto não elimina o problema do que fazer com esses equipamentos, somente o difere e transfere o problema para outra organização.

Para Knemeyer, Ponzurick e Logar (2002), recondicionar e reciclar são as melhores alternativas para coletar computadores que já estão obsoletos e podem virar lixo informático. Para isto, a aplicação de sistemas de logística reversa é fundamental para recuperação de produtos informáticos obsoletos. Deste modo, coletar e recondicionar computadores para melhorar seu desempenho e capacidade com algumas modificações prolonga sua vida útil para serem vendidos em outros mercados a preços mais baixos. É importante considerar que o recondicionamento de computadores não termina completamente com o problema do lixo informático, simplesmente estende o prazo de funcionamento do equipamento.

Por outro lado, a reciclagem consiste em coletar a totalidade de produtos de informática obsoletos para desmantelá-los em seus componentes básicos (vidro, metais e plástico) e reutilizá-los no mesmo setor ou em setores alternativos que demandem esses elementos como matéria-prima em seus processos da fabricação (KNEMEYER, PONZURICK; LOGAR, 2002). Segundo Carballo (2007) 75\% dos componentes de um computador podem ser aproveitados, mas $25 \%$ desses componentes estamos compostos de elementos perigosos como o chumbo e o cádmio, que causam danos no organismo.

\section{Metodologia de Pesquisa}

O objetivo fundamental de uma pesquisa é descobrir respostas para problemas mediante o emprego de procedimentos científicos (GIL, 1999). Neste contexto, para identificar o processo de logística reversa de computadores, impressoras, periféricos e componentes de produtos de informática no fim da vida útil ou com defeitos de fabricação, utilizado em uma empresa atacadista de informática, realizou-se um estudo de natureza exploratória, através do método de estudo de caso. De acordo com Yin (2001), o estudo de caso tem a vantagem de permitir o estudo aprofundado de um ou de poucos objetos em seu contexto real, embora tenha como limitação o fato de que seus resultados não podem ser extrapolados para outras situações.

A unidade de análise foi a empresa LOGIC, segunda maior atacadista de produtos informáticos do Equador, sendo entrevistados a Controller da empresa, encarregada das relações comerciais e contratuais com os fabricantes, o Chefe de Serviço ao Cliente, encarregado do processo de recepção e entrega dos produtos em garantia ou em serviço técnico, e o Chefe de Serviço Técnico que coordena o processo de reposição e reparação de produtos em garantia por defeitos ou falhas de fabricação, manuseio, manipulação errada e serviço técnico. As entrevistas e análises foram realizadas no mês de julho de 2007.

A coleta de dados foi realizada através de uma entrevista semi-estruturada por meio de perguntas abertas (Anexo 1), visando descrever como acontece o processo de logística reversa dos produtos em fim de vida útil, produtos de retorno para garantia por defeito de fabricação, manipulação incorreta, reparação e serviço técnico. Os objetivos das entrevistas foram:

- Identificar se os fabricantes proporcionam procedimentos de logística reversa para coleta de seus produtos/componentes em final de vida útil ou estragados;

- Identificar o destino (desmanche, reutilização, remanufatura e reciclagem) que se proporciona para esses produtos;

- Identificar os componentes reutilizados com maior freqüência no conserto de outros produtos;

- Identificar os produtos e componentes que não podem ser reutilizados e qual seu destino final;

- Identificar se o lixo informático gerado tem algum tratamento prévio antes de sua disposição final;

Identificar se existem lugares apropriados na cidade para alocar o lixo informático.

\section{Análise dos Resultados}

A empresa LOGIC Atacadista em Computação é a segunda maior empresa do Equador dedicada à comercialização e distribuição de computadores, peças e acessórios informáticos a nível nacional. Tem 35\% da participação de mercado a nível nacional, tendo como estratégia de negócio a 
diferenciação do produto e serviço. A diferenciação de produto é obtida pela exclusividade de marcas que os outros concorrentes não têm, enquanto a diferenciação do serviço é desenvolvida por atendimentos pós-venda e serviço técnico e de garantias. A área de Serviço Técnico e de Garantias é encarregada de tramitar a garantia quando o produto tem defeitos de fabricação e, além disso, nesta área se concertam produtos e se realizam serviços de manutenção.

Dentre os produtos que são comercializados, os mais importantes são: monitores, cases, motherboards, memórias, processadores, placasmãe, fontes de alimentação, placas de rede, laptops, computadores, impressoras, suprimentos de impressora, câmeras digitais, pendrives, discos duros, dispositivos óticos e magnéticos, MP3, PALMS, scanners, periféricos (mouse, teclado, webcams, microfones, caixas de som) entre outros. A venda destes produtos dá como resultado em média um faturamento mensal de dois milhões de dólares, distribuídos percentualmente como indica o Gráfico 1.

Gráfico 1: Distribuição de vendas por tipo de produto, 2007.

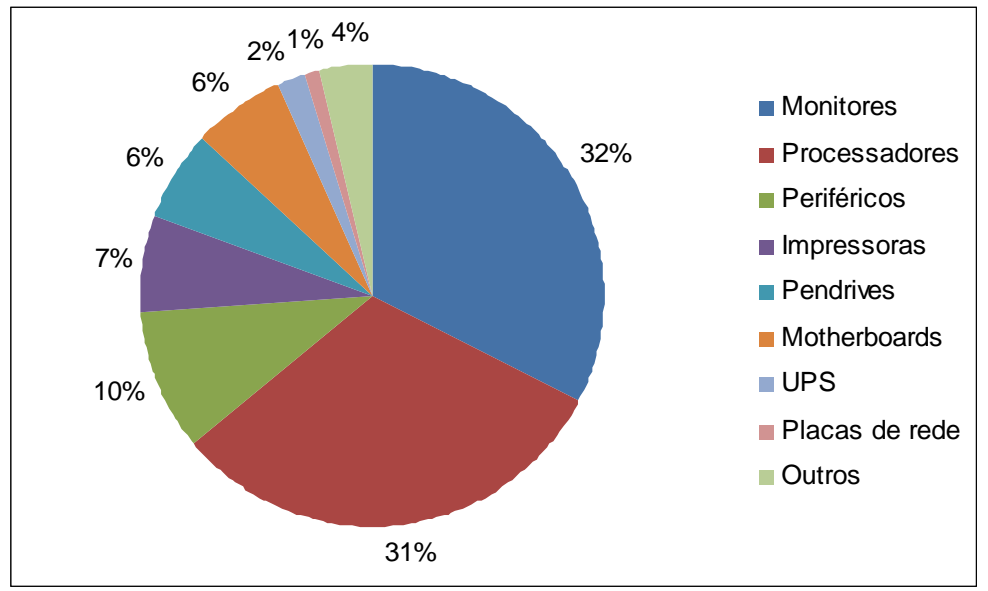

Para entender como trabalha um atacadista de informática é preciso descrever a cadeia de valor da empresa e como ela funciona. O processo começa em Miami onde uma filial da empresa realiza as negociações com os fabricantes para determinar as condições de produto, quantidade e preço. Os produtos são enviados de Miami, da China ou Coréia até o Equador, onde são vendidos a varejistas que, por sua vez, os revendem ao cliente final.

Os fabricantes pressupõem que, do pedido total de produtos que LOGIC faz, sempre existe um percentual com defeitos. Por tal motivo, além da quantidade pedida eles enviam uma quantidade adicional de produto, para que sejam entregues em garantia aos produtos com defeitos de fabricação. Este inventário de produtos adicional é denominado de estoque buffer.

Quando um cliente (varejista) compra um produto e ele está com defeito de fabricação, tem o direito de obter um produto novo, em função da garantia oferecida pelo fabricante. $O$ cliente simplesmente entrega o produto com defeito e ele recebe um novo produto. Depois, esse produto com defeito é revisado para determinar se pode ser consertado e vendido como produto remanufaturado ou se algum dos componentes dele serve para ser reusado em reparações futuras de outros produtos similares. Em último caso, é desmanchado e as peças em boas condições são vendidas.

Segundo os gestores, os fabricantes não proporcionam nenhuma política ou procedimento de logística reversa para coleta e disposição dos produtos no fim de vida útil ou estragados. Eles somente indicam que todos aqueles produtos devem ser armazenados em uma adega. Assim, a empresa determina um lugar específico para eles. Depois de um determinado tempo e com autorização do fabricante é feita a destruição das carcaças plásticas dos produtos - procedimento que se denomina "scrap de produto". Realiza-se um informe autenticado para depois destinar o lixo informático no aterro da cidade.

A empresa utiliza um sistema de logística reversa de pós-venda parcial (LEITE, 2006), pois revaloriza o produto que tem um defeito de fabricação e foi aplicada a garantia de marca. Esta revalorização se inicia com o desmanche e separação dos componentes que podem ser 
utilizados para consertar outros produtos com os mesmo danos. É o caso de computadores trazidos para manutenção e que precisam de componentes novos, mas cujo cliente não quer comprar uma nova peça por seu alto custo. Nesse caso, ele tem a opção de solicitar a utilização de um componente usado com um preço menor. Esses componentes também são utilizados no conserto de produtos em garantia de fábrica, ou são vendidos para outras empresas que consertam produtos de informática e que costumam comprar peças usadas para colocar nos equipamentos dos clientes. Em outros casos, as peças são usadas para o conserto de equipamentos de versões antigas e descontinuadas, onde o fabricante já não produz esse componente e somente pode ser obtido no mercado de peças usadas.

A logística reversa de pós-consumo (LEITE, 2006) não é feita pela empresa. Quando os produtos estão no fim de vida útil o proprietário (consumidor final) do produto os envia diretamente para disposição final. A empresa não realiza nenhum processo de reciclagem dos produtos, pois separar os componentes em seus elementos primários requer conhecimento e equipamentos especiais que a empresa não possui. Além, que esse tipo de tecnologia atualmente é muito cara. Para a LOGIC, não é economicamente viável adicionar esse processo, mesmo que certas peças tenham matérias úteis para serem usadas em outras indústrias- um exemplo são as placas-mãe compostas de silício, germânio e ouro - as quais atualmente são tratadas como lixo informático.

Os produtos ou peças mais reutilizadas para concerto de outros equipamentos são: carcaças de computador, fontes de alimentação, transistores de saída horizontal, fontes de alta voltagem, placas lógicas, placas de comunicações, ventiladores internos, transformadores, baterias, toners e cabos de dados. Estas peças são parte de computadores, impressoras, scanners e UPS principalmente. Já os produtos que mais retornam por defeitos de fabricação ou danos são monitores, impressoras, UPS, placas (lógicas, de alimentação, de comunicações) e certas peças internas do computador que sofrem danos por incompatibilidade. A empresa recebe, em média, aproximadamente 1130 produtos mensais para trâmite da garantia por defeitos de fabricação, dos quais 50 não têm nenhuma utilidade e são considerados como lixo informático para serem colocados em aterros sanitários.

Uma vez que todas as peças úteis são reutilizadas, as peças restantes que já constituem lixo informático não têm nenhum tratamento prévio antes de ser enviadas a seu destino final nos aterros sanitários. Segundo os gestores, não existe um controle da prefeitura sobre o tratamento do lixo informático. Ele é jogado fora de duas formas: a primeira é fazer pedaços menores do componente e misturá-lo com o lixo normal que é levado diariamente com a coleta de lixo da prefeitura. A segunda forma é levá-lo diretamente para o aterro sanitário, onde ele se junta aos diferentes tipos de lixo gerados pela cidade, já que não existe um aterro específico para este tipo de lixo. Seja qual for a forma de levar o lixo ao aterro, a prefeitura o enterra em um lugar específico, mas sem nenhum tipo de tratamento prévio. Assim, muitos dos componentes enterrados contêm chumbo como as baterias, fósforo branco, como os monitores CRT entres outros, o que origina grandes danos para 0 meio ambiente.

\section{Conclusões}

O eixo principal para que um sistema de logística reversa no setor de produtos informáticos seja bem sucedido depende do grau de comprometimento de todos os atores que conformam esta cadeia (Consumidor FinalVarejista-Atacadista-Fabricante). Neste sentido identificou-se um sistema de logística reversa de pós-venda e pós-consumo parcial originado principalmente pela aplicação de garantias de produtos com defeitos de fabricação. Estes produtos retornam até o nível do atacadista, o qual tenta revalorizar os produtos defeituosos, concertando-os para vendê-los como produtos remanufaturados, reaproveitando os componentes úteis para concertar outros equipamentos com danos iguais, e para vender as peças em mercados secundários de componentes usados.

Mesmo que o restante das peças e componentes que a empresa não consegue aproveitar possam ser recicladas, o atacadista não o realiza, porque tal processo de reciclagem não faz parte de seu foco de negócio, nem possui as capacidades (conhecimento e recursos) para fazer isto. Além, que montar uma unidade de reciclagem para este tipo de componentes tem um custo elevado que não representa o investimento realizado com o retorno gerado. Como Leite (2006) afirma, produtos duráveis de alto valor como computadores apresentam, por via regra, altos custos na fase industrial de desmontagem. Uma alternativa é destinar tais peças a indústrias que utilizem esses materiais como matéria-prima de seus processos de produção, reduzindo ainda mais o lixo informático que o setor gera.

Evidencia-se que os fabricantes não têm um adequado nível de comprometimento para que seus produtos tenham uma disposição final 
ambientalmente correta. Para que isto mude, devem existir políticas governamentais que regulem estas atividades tanto na indústria como no consumidor final. Assim toda a cadeia terá um grau de responsabilidade em cada etapa do ciclo de vida do produto. É obrigação dos fabricantes terem responsabilidade física e financeira do ciclo de vida de seus produtos, produzindo produtos de consumo não tóxicos e facilmente recicláveis. Talvez a conscientização do mercado consumidor seja também um fator importante para estimular as empresas a adotar estratégias que primam pela sustentabilidade, como por exemplo a utilização de processos de logística reversa.

A recuperação de produtos informáticos, o recondicionamento e remanufatura de computadores e periféricos, a reutilização de suas peças, a reciclagem de seus materiais, devem ser planejados e organizados sistemática e metodicamente por todos os atores sociais comprometidos com o assunto (Indústria, Governo, Consumidor). Somente com um planejamento multisetorial será possível reduzir o impacto ambiental originado pelo desperdício informático.

\section{Referências}

AHLUWALIA, P. K.; NEMA, A. K., A life cycle based multi-objective optimization model for the management of computer waste. Resources, Conservation and Recycling, v. 51, p. 792-826, 2007.

CARBALLO, E. El problema de descartar los equipos electrónicos: La basura electrónica y el caso del reuso. Disponível em: http://www.vitalis.net/actualidad131.htm. Acesso em: 05 jun. 2007.

CARROLL, C. Lixo high-tech. National Geographic. São Paulo, p. 38-57, jan. 2008.

ENVIRONMENTAL

PROTECTION ADMINISTRATION. Profile of the electronics and computer industry. United States Enviromental Protection Administration, Washington, v.2, n.36, p. 1-137, 1995.

GIL, A. C. Métodos e técnicas de pesquisa social. 5. ed. São Paulo: Atlas, 1999.

HART, S. L. A natural-resource-based view of the firm. The Academy of Management Review, v. 4, n. 20, p. 986-1014, 1995.

KANG, H.; SCHOENUNG, J. M. Electronic waste recycling: A review of U.S. infrastructure and technology options. Resources, Conservation and Recycling, n. 45, p. 368-400, 2005.

KNEMEYER, M.; PONZURICK, T.; LOGAR, C., A qualitative examination of factors affecting reverse logistics systems for end-of-live computers. International Journal of Physical Distribution \& Logistics Management, v. 32, n. 6, p. 455-459, 2002.

LEE, D.; DONG, M. A heuristic approach to logistics network design for de end-of-lease computers product recovery. Transportation Research, p. 220, 2007.

LEITE, P. R. Logística reversa, meio ambiente e competitividade. 2. ed. São Paulo: Pearson Prentice Hall, 2006.

LEITE, P. R. Logística reversa: categorias e práticas empresariais em programas implementados no Brasil: um ensaio de categorização In: ENCONTRO NACIONAL DE PROGRAMAS DE PÓS-GRADUAÇÃO EM ADMINISTRAÇÃO ANPAD, 30., 2003, São Paulo, SP. Anais. Brasília, 2005. 1 CD-ROM.

MARIEN, E. J. Reverse logistics as competitive strategy. Supply Chain Management Review, p. 43-52, 1998.

MOLLENKOPF, D. A.; CLOSS, D. J. The hidden value in reverse logistics. Supply Chain Management Review, v.9, n.5, jul./aug. 2005.

MURPHY, P.; POIST, R. Green logistics strategies: an analysis of usage patters. Transportation Journal, v. 40, n. 2, p. 5-17, 2000.

OPCIONS. Els ordinadors. Revista Opcions, p. 521, 2003. Disponível em: http://cric.pangea.org/pdf/op62.pdf. Acesso em: 05 jun. 2007.

RAVI, V.; SHANKAR, R. Productivity improvement of a computer hardware supply chain. International Journal of Productivity and Performance Management, v. 54, n. 4, p. 239-255, 2005.

RAVI, V.; SHANKAR, R.; TIWARI, R. M. Analyzing alternatives in reverse logistics for end-of-life computers: ANP and balanced scorecard approach. Computers \& Industrial Engineering, v. 48, p. 327-356, 2005.

ROGERS, D. S.; TIBBEN-LEMBKE, R. S. Going backwards: reverse logistics trends and practices. Pittsburgh: Reverse Logistics Executive Council: Center for Logistics Management, 1998.

SALINAS, A. C. Material informático y contaminación medioambiental. Disponível em: www.xtec.es/ acastan/textos. Acesso em: 05 jun. 2007. 
SHIH, L., Reverse logistics system planning for recycling electrical appliances and computers in Taiwan. Resources Conservation and Recycling, v. 31, p. 55.72, 2001.

STOCK, J. R. Reverse Logistics Programs. Illinois: Council of Logistics Management, 1998

TAN, A.; YU, W.; ARUM, K. Improving the performance of a computer company in supporting its reverse logistics in the Asia-Pacific region. International Journal of Physical Distribution and Logistics Management, v. 33, n. 2, p. 59-74, 2003.

WILLIAMS, E. D., Environmental impacts of microchip manufacture. The Solid Things, v. 461, n. 1, p. 2-6, 2004.

WILLIAMS, E.; ARYES, R.; HELLER M. The 1.7 kilogram microchip: energy and material use in the production of semiconductor devices. Environmental Science and Technology, v. 36, n. 24, p. 5504-5510, 2002.

YIN, R. Estudo de caso: planejamento e métodos. Porto Alegre: Bookman, 2001. 